\section{POVEZANOST IZMEĐU \\ POKAZATELJA DRŽANJA \\ TIJELA I DOMINANTNE RUKE SA \\ SKOLIOTIČNIM TJELESNIM \\ DRŽANJEM KOD RUKOMETAŠA}

\author{
CONNECTION BETWEEN BODY \\ POSTURE INDICATORS AND \\ DOMINANT HAND WITH \\ SCOLIOTIC BODY POSTURE IN \\ HANDBALL PLAYERS
}

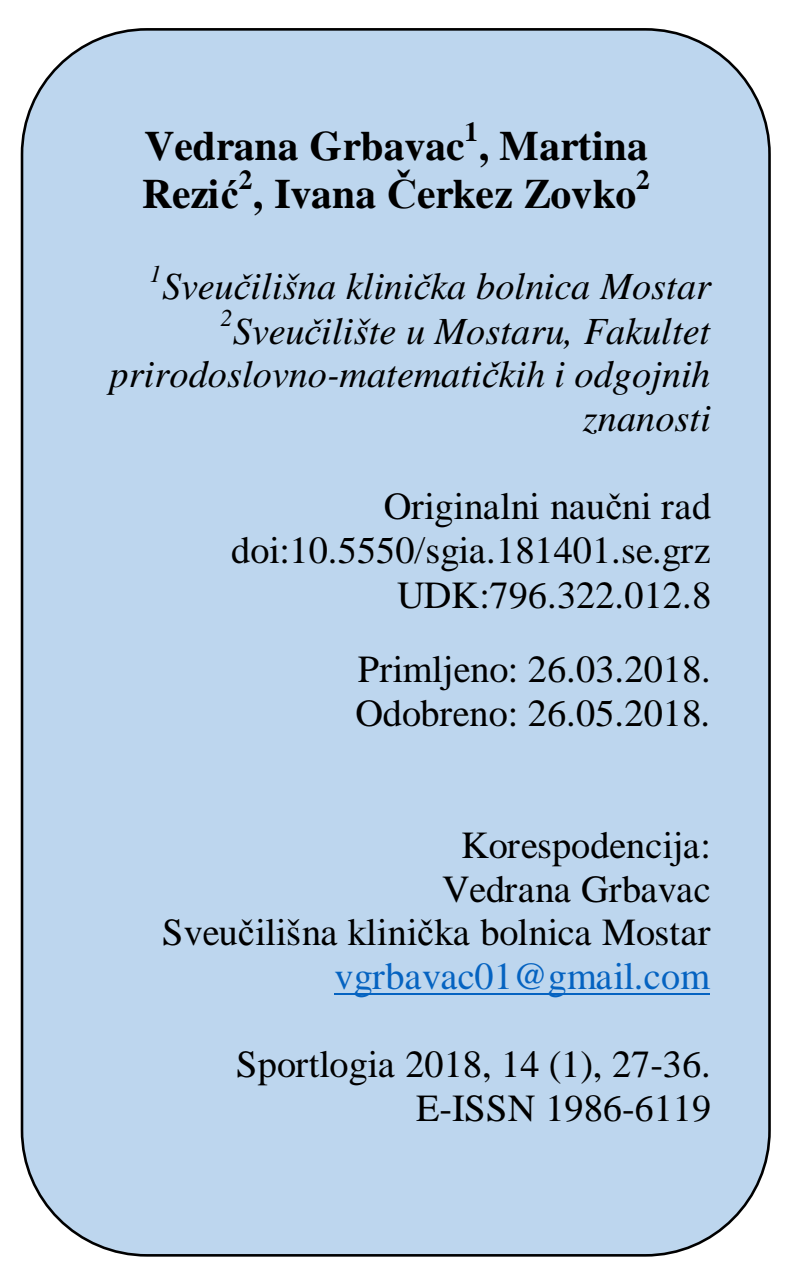

Korespodencija:

Vedrana Grbavac

\title{
SAŽETAK
}

Suvremeni način života uzrok je sve veće pojave nepravilnih tjelesnih držanja kod djece $i$ adolescenata. Kod sportaša nepravilna tjelesna držanja mogu izazvati brojne kronične zdravstvene probleme i ozljede koje utječn na njihovu uspješnost u sportu. Rukometnu igru karakterizira dinamičnost i pokretljivost, uz stalne i brze promjene položaja tijela i elemenata tehnike. Zbog određenih karakteristika rukometa kao sporta (dijelovi tehnike koji su asimetrični zbog igranja jednom rukom) postoji osnovana sumnja, da su rukometaši izloženi faktorima koji mogu uzrokovati razvoj posturalnih deformiteta. Cilj istraživanja bio je ispitati je li skoliotično držanje česta pojava u adolescenata koji treniraju rukomet, te postoji li povezanost između relevantnih pokazatelja nepravilnog držanja $i$ dominantne ruke sa skoliotičnim tjelesnim držanjem kod rukometaša. Istraživanje je provedeno na uzorku 98 adolescenata u dobi od 13-18 godina koji su uključeni u trenažni proces preko tri godine, a testirani su kliničkim Adamsovim testom pretklona. Za utvrđivanje tipova tjelesnog držanja primijenjen je posteriorni pregled. Uzorak varijabli za procjenu tjelesnog držanja sadržavao je numeričke vrijednosti osam referentnih točaka u posteriornom pregledu. Za utvrđivanje razlika između skupina u varijablama upitnika, te kod utvrđivanja razlike između ispitanika kod varijabli dobivenih iz upitnika, korišten je Hi kvadrat test, te je određena kontingencijska tablica s frekvencijama i postotcima. Ustanovljena je značajna razlika između desnostranog $i$ normalnog tjelesnog držanja, gdje su ispitanici s desnostranim držanjem značajno više godina proveli trenirajući rukomet $u$ odnosu na one sa normalnim držanjem, što navodi na zaključak kako ovaj sport može da se povezuje uz pojavu skoliotičnog držanja.

Ključne riječi: držanje tijela, dominantna ruka, skoliotično držanje, rukomet.

Grbavac, V., Rezić, M., \& Zovko, I. (2018). Povezanost između pokazatelja držanja tijela i dominantne ruke sa skoliotičnim tjelesnim držanjem kod rukometaša. Sportlogia, 14 (1), 27-36. doi:10.5550/sgia.181401.se.grz

Stranica 27. 


\section{UVOD}

Problem današnjice je hipokinezija (stanje smanjenog kretanja) koja dovodi do neravnomjernog razvoja pojedinih mišićnih skupina. Zanemareni paramorfizmi, osobito u doba razvoja, mogu preći u dismorfizme koji zahtijevaju dugotrajno i mukotrpno liječenje. Nepravilna tjelesna držanja nastala zbog oslabljene strukture posturalnih mišića koja su utvrđena tijekom rasta i razvoja, a osobito ona koja su otkrivena u ranoj životnoj dobi, mogu se korigirati dodatnim programima tjelesnog vježbanja. Rana, tj. pravodobna dijagnoza jest najvažniji element uspješnog liječenja (Paušić, 2007). Iako je, generalno gledajući, jasno da tjelesna aktivnost višestruko pozitivno djeluje na pojedine organske sustave i ljudske organizme u cjelini, međutim liječnici sportske medicine ukazuju na povećanu učestalost nepravilnih držanja i deformiteta kod onih koji su aktivno uključeni u sportske aktivnosti (Kosinac, 2002). Profesionalni sport ima svojih negativnosti, a većinom se te negativnosti mogu reflektirati na zdravlje sportaša.

Rukomet je sport kompleksnih polistrukturalnih gibanja u kojima postoji čitav niz različitih kretnji (dokorak, križni korak...), skokova (u smeču, bloku, šutu...), bacanja i padova (upijač, rolanje...), sprintova, statičkih izdržaja u stavovima, udaraca (Janković, Marelić i Janković, 2003). Tehnički elementi rukometa, koji su asimetrični zbog izvođenja jednom rukom, ukazuju na postojanje vjerovatnoće da su rukometaši izloženi faktorima koji mogu uzrokovati razvoj posturalnih deformiteta. Asimetričan oblik opterećenja u kombinaciji sa velikim brojem skokova i doskoka na tvrdim podlogama može vrlo nepovoljno utjecati na lokomotorni aparat. Naglo izrastanje u adolescentskom zamahu rasta te nemogućnost mišićno-koštanog sustava da poprati te nagle promjene dovodi do nepravilnih tjelesnih držanja (skolioze, kifoze, lordoze). Budući da nepravilno tjelesno držanje može poprimiti različite oblike, ti oblici su definirani od strane raznih autora kroz tipove tjelesnog držanja (Aagaard i Jørgensen, 1996). U literaturi se ne nudi veliki broj radova koji su istraživali skoliotično držanje i njegovu povezanost sa sportom, posebice rukometom. Rezultati ovog istraživanje imaju svrhu pokazati posebnosti rukometa i njegovu vezu sa skoliotičnim držanjem. Cilj istraživanja bio je ispitati je li skoliotično držanje česta pojava u adolescenata koji treniraju rukomet, te postoji li povezanost između relevantnih pokazatelja nepravilnog držanja i dominantne ruke sa skoliotičnim tjelesnim držanjem kod rukometaša.

\section{METODE}

Istraživanje je provedeno na uzorku 98 adolescenata muškog pola koji treniraju rukomet u rukometnom klubu „MI Izviđač“ Ljubuški. Svi sportaši u dobi od 13-18 godina, a koji su uključeni u trenažni proces preko tri godine, testirani su kliničkim Adamsovim testom pretklona (Theologis, Fairbank, Turner-Smith i Pantayopoulos, 1997). Nakon testa pretklona izvršena je procjena viskom kako bi se procijenila odstupanja kralježnice u frontalnoj ravni te antropološka mjerenja kojim je dobijen podatak o bilateralnoj razlici. Za utvrđivanje tipova tjelesnog držanja primijenjen je posteriorni pregled. Uzorak varijabli za procjenu tjelesnog držanja sadržava numeričke vrijednosti osam referentnih točaka u posteriornom pregledu (Paušić, 2007). Određivanje tipova tjelesnog držanja napravljeno je pomoću viska uz fotografiranje svakog ispitanika kako bi se dobio što objektivniji rezultat.

Pokazatelji tjelesnog držanja u posteriornom pogledu:

- PUHO - postavljanjem markacija na gornji rub lijevog i desnog uha, može se ustvrditi odstupanja linije koja povezuje dvije markacije od horizontale u stupnjevima i centimetrima, ako je lijeva strana spuštena (-),ako je lijeva strana povišena (+)

Grbavac, V., Rezić, M., \& Zovko, I. (2018). Povezanost između pokazatelja držanja tijela i dominantne ruke sa skoliotičnim tjelesnim držanjem kod rukometaša. Sportlogia, 14 (1), 27-36. doi:10.5550/sgia.181401.se.grz 
- PRAM - postavljanjem markacija na najviši vrh lijevog i desnog ramena: acromion, može se ustvrditi odstupanja linije koja povezuje dvije markacije od horizontale u stupnjevima i centimetrima, ako je lijeva strana spuštena (-), ako je lijeva strana povišena (+)

- PLOPG - postavljanjem markacija na lijevi i desni angulus superior lopatica, može se ustvrditi odstupanja linije koja povezuje dvije markacije od horizontale u stupnjevima i centimetrima, ako je lijeva strana spuštena (-),ako je lijeva strana povišena (+)

- PLOPD - postavljanjem markacija na lijevi i desni angulus inferior lopatica, može se ustvrditi odstupanja linije koja povezuje dvije markacije od horizontale u stupnjevima i centimetrima, ako je lijeva strana spuštena (-), ako je lijeva strana povišena (+)

- PZDJ - postavljanjem markacija na lijevu i desnu spinu illiacu superior posterior, može se ustvrditi odstupanja linije koja povezuje dvije markacije od horizontale u stupnjevima i centimetrima, ako je lijeva strana spuštena (-), ako je lijeva strana povišena (+)

- PKOL - postavljanjem markacija na lijevi i desni epicondylus medialis, može se ustvrditi odstupanja linije koja povezuje dvije markacije od horizontale u stupnjevima i centimetrima, ako je lijeva strana spuštena (-), ako je lijeva strana povišena (+)

- PNZG - postavljanjem markacija na lijevi i desni malleolus medialisa, možem se ustvrditi odstupanja linije koja povezuje dvije markacije od horizontale u stupnjevima i centimetrima, ako je lijeva strana spuštena (-), ako je lijeva strana povišena (+).

- PKRALJ - postavljenjem markacija na processus spinosus vertebrae, može se ustanoviti odstupanja linije koja povezuje markacije kralježaka sa linijom viska, ako je devijacija kralježnice u lijevu stranu (-), ako je devijacija kralježnice u desnu stranu $(+)$.

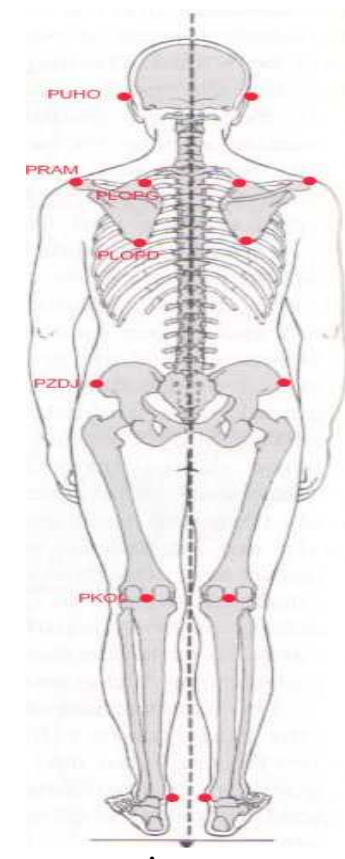

Slika 1. Referentne točke u posteriornom pregledu tjelesnog držanja (17)

Obrada podataka koji su prikupljeni navedenim eksperimentalnim postupkom izvršena je za svaki razred posebno (po dobi) te su svi podaci obrađeni statističkim paketom Statistica 7 (StatSoft, USA), te SPSS 16 (USA). 
Za utvrđivanje tipova tjelesnog držanja korištena je K-means metoda klaster (taksonomske) analize (Hartigan, 1978) koja se upotrebljava s ciljem određivanja broja skupina maksimalno različitih ispitanika, a pomoću koje se analizom varijance mogu utvrditi razlike između skupina u svakom pokazatelju. Ova metoda omogućuje samostalno definiranje broja skupina.U okviru ove metode korišteni su sljedeći parametri: deskriptivni parametri: aritmetička sredina (AS) i standardna devijacij (SD), pokazatelji analize varijance (F vrijednost, p- razina značajnosti), broj ispitanika u svakoj skupini, pripadnost ispitanika pojedinoj skupini.

Za utvrđivanje razlika između skupina u varijablama upitnika, te kod utvrđivanja razlike između ispitanika kod varijabli dobivenih iz upitnika, korišten je Hi kvadrat test, te je određena kontingencijska tablica s frekvencijama i postotcima

\section{REZULTATI}

U ovom poglavlju predočeni su rezultati istraživačkog rada koji odgovaraju na postavljene ciljeve. U nastavku su prikazani podatci podaci dobiveni statističkom obradom. Analizom su ispitanici podijeljeni u tri skupine na osnovu tipa tjelesnog držanja koje sa statistički značajno razlikuju.

Tablica 2. Tip tjelesnog držanja

\begin{tabular}{|l|c|c|}
\hline Tip tjelesnog držanja & Broj ispitanika & Postotak \% \\
\hline Lijevostrano skoliotično držanje & 16 & 16,3 \\
\hline Normalno tjelesno držanje & 34 & 34,7 \\
\hline Desnostrano skoliotično držanje & 48 & 49,0 \\
\hline Ukupno & 98 & 100 \\
\hline
\end{tabular}

$\mathrm{U}$ ispitivanom uzorku, najučestalije su bili zastupljeni ispitanici sa desnostranim skoliotičnim držanjem $\left(\chi^{2}\right.$ test $\left.=15,755 ; \mathrm{df}=2 ; \mathrm{P}<0,001\right)$.

Tablica 3. Prikaz dešnjaka i lijevaka s obzirom na tip tjelesnog držanja

\begin{tabular}{|r|c|c|c|c|c|}
\hline \multirow{2}{*}{ Dominantna ruka } & \multicolumn{3}{|c|}{ Tip tjelesnog držanja } & \multirow{2}{*}{ Total } \\
\cline { 3 - 6 } & & Lijevostrano & Normalno & Desnostrano & Count \\
\multirow{2}{*}{ Desna } & 12 & 31 & 46 & 89 \\
\cline { 2 - 6 } & $\%$ within Tip držanja & $75,0 \%$ & $91,2 \%$ & $95,8 \%$ & $90,8 \%$ \\
\hline \multirow{2}{*}{ Lijevan } & Count & 4 & 3 & 2 & 9 \\
\cline { 2 - 6 } & $\%$ within Tip držanja & $25,0 \%$ & $8,8 \%$ & $4,2 \%$ & $9,2 \%$ \\
\hline Total & Count & 16 & 34 & 48 & 98 \\
\cline { 2 - 6 } & $\%$ within Tip držanja & $100,0 \%$ & $100,0 \%$ & $100,0 \%$ & $100,0 \%$ \\
\hline
\end{tabular}

Ispitanici sa dominantnom desnom rukom značajno su učestalije imali desnostrano skoliotično držanje, u odnosu na ispitanike s dominantnom lijevom rukom $\left(\chi^{2}\right.$ test=6,253; $\mathrm{df}=2 ; \mathrm{P}=0,044)$. Lijevostrano skoliotično držanje ustanovljeno je kod 16 ispitanika, od čega je $12(75,0 \%)$ dešnjaka, $4(25,0 \%)$ ljevaka. Normalno tjelesno držanje pokazuju 34 ispitanika, od koji je $31(91,2 \%)$ ispitanik sa dominantnom desnom rukom, a $3(8,8 \%)$ ispitanika sa lijevom 
rukom. Desnostrano skoliotično držanje dokazano je kod 48 ispitanika, kojih čine $46(95,8 \%)$ dešnjaka i $2(4,2 \%)$ lijevaka.

Tablica 11. Prikaz pozicija igrača i tip tjelesnog držanja

\begin{tabular}{|c|c|c|c|c|c|}
\hline \multirow{2}{*}{\multicolumn{2}{|c|}{ Pozicija igrača }} & \multicolumn{3}{|l|}{ Tip držanja } & \multirow{3}{*}{$\frac{\text { Total }}{8}$} \\
\hline & & \multirow{2}{*}{\begin{tabular}{|l|} 
Lijevostrano \\
2
\end{tabular}} & \multirow{2}{*}{$\begin{array}{l}\text { Normalno } \\
2\end{array}$} & \multirow{2}{*}{\begin{tabular}{|l}
$\begin{array}{l}\text { Desnostran } \\
\text { o }\end{array}$ \\
4 \\
\end{tabular}} & \\
\hline Desni vanjski & Count $\%$ within & & & & \\
\hline & Tip držanja & $12,6 \%$ & $5,9 \%$ & $8,4 \%$ & $8,2 \%$ \\
\hline \multirow[t]{2}{*}{ Desno krilo } & Count \% within & 5 & 3 & 3 & 11 \\
\hline & Tip držanja & $31,3 \%$ & $8,8 \%$ & $6,3 \%$ & $10,2 \%$ \\
\hline \multirow[t]{2}{*}{ Golman } & Count \% within & 0 & 6 & 9 & 15 \\
\hline & Tip držanja & $0,0 \%$ & $17,6 \%$ & $18,8 \%$ & $15,3 \%$ \\
\hline \multirow[t]{2}{*}{ Lijevi vanjski } & Count \% within & 1 & 5 & 4 & 10 \\
\hline & Tip držanja & $6,3 \%$ & $14,7 \%$ & $8,3 \%$ & $10,2 \%$ \\
\hline \multirow[t]{2}{*}{ Lijevo krilo } & Count $\%$ within & 3 & 4 & 16 & 23 \\
\hline & Tip držanja & $18,8 \%$ & $11,8 \%$ & $33,3 \%$ & $23,5 \%$ \\
\hline \multirow[t]{2}{*}{ Pivot } & Count \% within & 4 & 9 & 8 & 21 \\
\hline & Tip držanja & $25,0 \%$ & $26,5 \%$ & $16,7 \%$ & $22,4 \%$ \\
\hline \multirow{2}{*}{$\begin{array}{l}\text { Srednji } \\
\text { vanjski }\end{array}$} & Count $\%$ within & 1 & 5 & 4 & 10 \\
\hline & Tip držanja & $6,3 \%$ & $14,7 \%$ & $8,3 \%$ & $10,2 \%$ \\
\hline \multirow[t]{2}{*}{ Total } & Count $\%$ within & 16 & 34 & 48 & 98 \\
\hline & Tip držanja & $100,0 \%$ & $100,0 \%$ & $100,0 \%$ & $100,0 \%$ \\
\hline
\end{tabular}

Nije postojala značajna razlika u omjeru pozicije igrača ovisno o tipu držanja (Monte Carlo metoda, $\mathrm{P}=0,192$ ).

Tablica 13. Prikaz držanja ispitanika i godina treniranja rukometa

\begin{tabular}{|l|l|l|l|l|l|}
\hline & & & $\begin{array}{l}\text { Std. } \\
\text { Deviation }\end{array}$ & Minimum & Maximum \\
\hline Lijevostrano & 16 & 4,44 & 1,36 & 1 & 6 \\
Normalno & 34 & 4,24 & 1,39 & 1 & 7 \\
Desnostrano & 48 & 5,15 & 1,68 & 1 & 9 \\
Total & 98 & 4,71 & 1,58 & 1 & 9 \\
\hline
\end{tabular}

Broj godina treniranja značajno se razlikovao između tipova skoliotičnog držanja $(\mathrm{F}(2,97)=3,775 ; \quad \mathrm{P}=0,026)$. Posthoc testovima pokazala se značajna razlika između desnostranog i normalnog držanja (Posthoc Tukey test, $\mathrm{P}=0,026$ ), gdje su ispitanici s desnostranim skoliotičnim držanjem proveli značajno više godina treniranja rukometa $u$ odnosu na normalno držanje. 
Srednja vrijednost godina treniranja bila je 4,71 $\pm 1,5$ godina. Minimalan broj godina treniranja bila je 3, a maksimalan broj godina treniranja bilo je 9 godina.

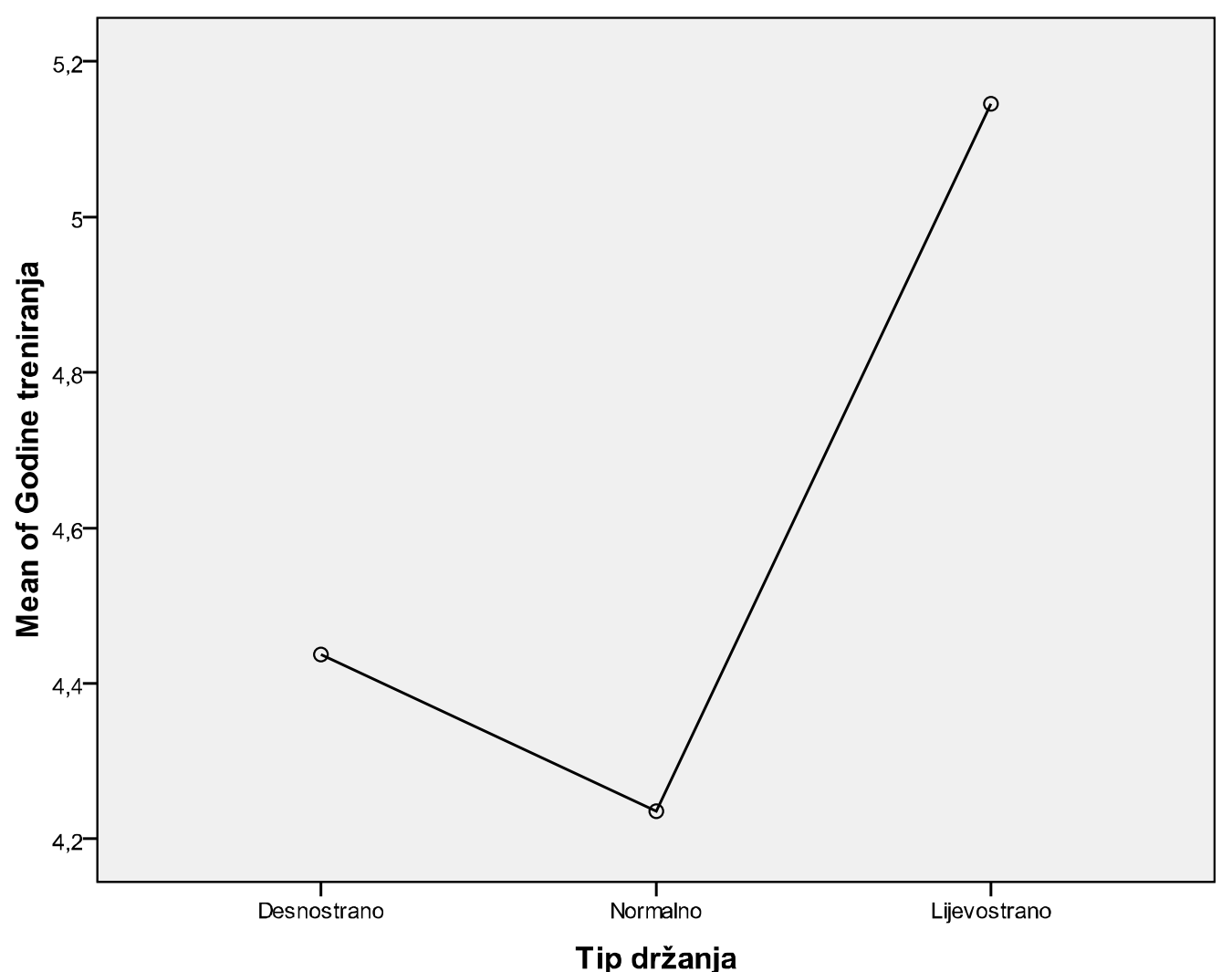

Slika 2. Prikaz ispitanika s obzirom na tip držanja i godine treniranja

\section{DISKUSIJA}

Ispitanici s dominantnom desnom rukom značajno su učestalije imali desnostrano skoliotično držanje, u odnosu na ispitanike s dominantnom lijevom rukom $\left(\chi^{2}\right.$ test $=6,253$; $\mathrm{df}=2 ; \mathrm{P}=0,044)$. Lijevostrano skoliotično držanje ustanovljeno je kod 16 ispitanika, od čega je $12(75,0 \%)$ dešnjaka, $4(25,0 \%)$ lijevaka. Normalno tjelesno držanje pokazuju 34 ispitanika, od koji je $31(91,2 \%)$ ispitanik sa dominantnom desnom rukom, a $3(8,8 \%)$ ispitanika sa lijevom rukom. Desnostrano skoliotično držanje dokazano je kod 48 ispitanika, kojih čine 46 $(95,8 \%)$ dešnjaka i 2 (4,2\%) lijevaka. Zaključak je kako osobe sa dominantnom desnom rukom imaju značajno češće desnostrano skoliotično držanje, u odnosu na one sa dominantnom lijevom rukom, gdje ta razlika nije pronađena kao statistički značajna. U općoj populaciji gotovo 90\% ljudi su dešnjaci (Incel, Ceceli, Durukan, Erdem i Yorgancioglu, 2002). Goldberg i sur. (1990) su u dešnjaka pronašli povezanost između korištenja ruke i prevladavanja desne strane torakalne krivine u adolescentnih idiopatskih skolioza. No, ova povezanost nije bila potvrđena u ljevoruke djece, utvrđeno je da je smjer zakrivljenosti kralježnice u ovoj skupini slučajno raspodijeljen. Hansgerd (1998) dokazao je kako sport u kojem su specifična naprezanja za gornji ekstremitet uglavnom jednostrana, tijekom rasta može dovesti do promjena u mekih tkiva i kosti. Istraživanje provedeno na profesionalnim tenisačima pokazalo je hipertrofiju kosti nadlaktice na rendgenskim snimcima na dominantnoj 
ruci, tj. onoj koja aktivnija u sportu. Razlika u kortikalnoj debljini kosti dominantne i nedominantne ruke je odgovor na vježbanje i pojačani fizički napor (Jones, Priest, Hayes, Tichenor i Nagel, 1977).

Omjer tipa tjelesnog držanja sa pozicijom igrača u rukometu pokazala je da je najveći broj igrača s desnostranim skoliotičnim držanjem na poziciji lijevo krilo $(33,3 \%)$, a najmanje na mjestu desnog krila $(6,3 \%)$. Igračka pozicija koja broji najveći broj igrača sa normalnim držanjem je pivot (26,5\%), a najmanje na mjestu desni vanjski (5,9\%). Lijevostrano skoliotično držanje najzastupljenije je među igračima na poziciji desno krilo $(31,3 \%)$, a čak ni jedan na poziciji golmana. Statistički značajna razlika nije dokazana. Prethodna istraživanja navode da se igrači na pojedinim pozicijama značajno razlikuju jedni od drugih u nekim morfološkim parametrima, pogotovo u tjelesnoj visini i potkožnom masnom tkivu (Chinn, Priest i Kent 1974; Hansgerd, Andreas, Gerd i Alfried-Krupp, 1998; Sporiš, Èanaki i Barišić, 2007; Pieper, 1997). Uočene su razlike u tjelesnoj visini između bek i krilnih igrača i u količini tjelesne masti između vratara i ostalih igrača u timu (Hansgerd, Andreas, Gerd i Alfried-Krupp, 1998; Pieper, 1997; Sporiš, Èanaki i Barišić, 2007). Sve navedeno može biti razlog spomenutoj raspodjeli tjelesnog držanja u rukometaša. Istraživanje je pokazalo da su godine treninga u pozitivnoj korelaciji sa dužinom šake (Spearman's rho=0,288; $\mathrm{P}=0,004$ ). Razlika u dužini ruke bila je u pozitivnoj korelaciji s razlikom u dužini šake (Spearman's rho=0,317; $\mathrm{P}=0,001$ ) kao i s razlikom u obujmu nadlaktice (Spearman's rho=0,304; $\mathrm{P}=0,002$ ). Razlika u dužini šake bila je u pozitivnoj korelaciji s razlikom u obujmu nadlaktice (Spearman's rho=0,523; $\mathrm{P}<0,001$ ). Prsti su najmanji, najlakši dijelovi motornog aparata, stoga oni predstavljaju dijelove koji najlakše mogu preusmjeriti snagu lopte, ali u isto vrijeme, kontrola lopte preko prstiju je posebno važna za točnost različitih šuteva u rukometu. Tipovi skoliotičnog držanja značajno se razlikuju prema godinama treniranja rukometa $\mathrm{F}(2,97)=3,775 ; \mathrm{P}=0,026)$. Indeks simetrije lijeve i desne ruke u promatranim veličinama (dužina ruke, dužina šake i obujam nadlaktice) nije se pokazala kao značajna razlika $\mathrm{s}$ obzirom na tipove tjelesnog držanja u frontalnoj ravni. 


\section{ZAKLJUČAK}

U ovom istraživanju utvrđeno je da je najveći broj igrača s desnostranim skoliotičnim držanjem na poziciji lijevo krilo, a najmanje na mjestu desnog krila, te da je pivot igračka pozicija koja broji najveći broj igrača sa normalnim držanjem, a najmanje na mjestu desni vanjski. Takođe je utvrđeno da je lijevostrano skoliotično držanje najzastupljenije među igračima na poziciji desno krilo, a čak ni jedan na poziciji golmana. Ustanovljena je značajna razlika između desnostranog i normalnog tjelesnog držanja, gdje su ispitanici s desnostranim držanjem značajno više godina proveli trenirajući rukomet u odnosu na one sa normalnim držanjem, što navodi na zaključak kako ovaj sport može da se povezuje uz pojavu skoliotičnog držanja.

\section{LITERATURA}

Aagaard, H., \& Jørgensen, U. (1996). Injuries in elite volleyball. Scand J Med Sci Sports, $6(4), 228-232$.

https://doi.org/10.1111/j.1600-0838.1996.tb00096.x

PMid:8896096

Chinn, C. J., Priest, J. D., \& Kent, B. E. (1974). Upper Extremity Range of Motion, Grip Strength, and Girth in Highly Skilled Tennis Players. Phys Ther, 54(5), 474-483. https://doi.org/10.1093/ptj/54.5.474

PMid:4423510

Goldberg, C. \& Dowling, F. (1990). Handedness and scoliosis convexity: a reappraisal. Spine Phila Pa, 15(2), 61-4.

https://doi.org/10.1097/00007632-199002000-00001

PMID:2326712

Hansgerd, P., Andreas, K., Gerd, Q., \& Alfried-Krupp, K. (1998). Muscular imbalances in elite handball players - practicconsequences with respect to the prevention of injuries. In H. J. Riehle, \& M. M. Vieten (Eds.), Proceedings II: 16 international symposium on biomechanics in sports (pp. 325-328). Konstanz, GER. University of Konstanz.

Hansgerd, P. (1998). Humeral Torsion in the Throwing Arm of Handball Players, Am. J. Sports Med. 26(2), 247-253.

https://doi.org/10.1177/03635465980260021501

PMid:9548119

Incel, N., Ceceli, E., Durukan, P., Erdem, H., \& Yorgancioglu, Z. (2002). Grip strength: effect of hand dominance. Singapore Med J. 43(5), 234-7. PMid:12188074

Janković, V., Marelić, N., \& Janković, G. (2003). Suvremeni model metodike treninga u školskom sportu. In V. Findak i K. Delija (Eds.), Zbornik radova, 12. Ljetna škola kineziologa Republike Hrvatske (pp. 147- 150). Rovinj, HR. Hrvatski kineziološki savez.

Jones, H., Priest, J., Hayes, E., Tichenor, C., \& Nagel, D. Humeral hypertrophy in response to exercise, J Bone Joint Surg Am 59(2), 204-208. PMid:845205

Kosinac, Z. (2002). Kineziterapija sustava za kretanje. Split, HR: Sveučilište u Splitu, Kineziološki fakultet. 
Paušić, J. (2007). Konstrukcija i vrednovanje mjernih postupaka za procjenu tjelesnog držanja u dječaka od 10 do 13 godina. Doktorska disertacija. Kineziološki fakultet, Sveučilišta u Zagrebu.

Pieper, H. G. (1997). Humeral Torsion in Recurrent Shoulder Dislocation - A Radiological Comparison of 240 Stable and 300 Unstable Shoulders. Orthop. Trans 21(1), 102-103.

Sporiš, G., Èanaki, M., \& Barišić, V. Morphological differences of elite Croatian female soccer players according to them position. Hrvatski sportskomedicinski vjesnik, 22(2), 91-96.

Theologis, T. N., Fairbank, J.C., Turner-Smith, A.R., Pantayopoulos, T. (1997). Early detection of progression in adolescent idiopathic scoliosis by measurement of changes in back shape with the integrated shape imaging system scanner. Spine 22(11), 223-7.

https://doi.org/10.1097/00007632-199706010-00010 


\begin{abstract}
The modern way of life is the cause of the increasing occurrence of improper body posture in children and adolescents. In athletes, improper body posture can lead to numerous chronic health problems and injuries that affect their performance in sports. The handball game is characterized by dynamism and mobility, with constant and rapid changes of body positions and technique elements. Due to certain characteristics of handball as a sport (parts of the technique that are asymmetric due to playing with one hand) there is a reasonable doubt that handball players are exposed to factors that can cause a development of postural deformities. The aim of the study is to investigate whether scoliotic posture is a frequent occurrence in adolescents who train handball, and whether there is a correlation between the relevant indicators of improper body posture and the dominant hand with scoliotic body posture in handball players. The study was conducted on a sample of 98 adolescents aged 1318 who had been involved in the training process for over three years and were tested with clinical Adams forward bend test. A posterior examination was used to determine the types of body posture. The sample of variables for the assessment of body posture contained numerical values of eight reference points in the posterior examination. To determine the differences between groups in variables of the questionnaire, and in determining the difference between the respondents in the variables obtained from the questionnaire, the Chisquare test was used, and a contingency table with frequencies and percentages was determined. A significant difference was found between right-sided and normal body posture, where right-sided posture subjects spent significantly more years training a handball compared to those with normal body posture, which suggests that this sport can be associated with the occurrence of a scoliotic posture.
\end{abstract}

Key words: body posture, dominant hand, scoliotic posture, handball.

Primljeno: 26.03.2018. Odobreno: 26.05.2018.

Korespodencija: Vedrana Grbavac Sveučilišna klinička bolnica Mostar vgrbavac01@gmail.com 